\title{
Neurosensory dysphagia in a COVID-19 patient
}

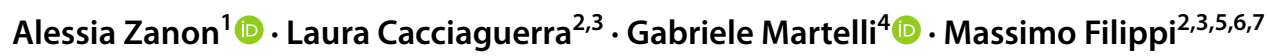

Received: 16 March 2021 / Revised: 30 March 2021 / Accepted: 1 April 2021 / Published online: 19 April 2021

(c) Springer-Verlag GmbH Germany, part of Springer Nature 2021

Keywords COVID-19 · Neurosensory dysphagia · Fibro-endoscopic evaluation of swallowing · Transmembrane Protease Serine 2

\begin{tabular}{|c|c|}
\hline \multicolumn{2}{|c|}{ Abbreviations } \\
\hline COVID-19 & Corona Virus Disease 2019 \\
\hline FEES & $\begin{array}{l}\text { Fibro-endoscopic evaluation of } \\
\text { swallowing }\end{array}$ \\
\hline PAS & Penetration Inhalation Scale \\
\hline ARDS & Acute Respiratory Distress Syndrome \\
\hline SARS-CoV-2 & $\begin{array}{l}\text { Severe Acute Respiratory Syndrome } \\
\text { Corona Virus } 2\end{array}$ \\
\hline TMPRSS2 & Transmembrane Protease Serine 2 \\
\hline
\end{tabular}

Dear Sirs,

We describe the case of a 72-year-old man admitted to the hospital with COVID-19 pneumonia. The neurological history and exam were unremarkable.

Due to respiratory worsening, oro-tracheal intubation and repeated courses of pronation became mandatory after 1 week. As gas exchanges improved, the patient weaned from the ventilator and self-extubated after 14 days. We performed a bedside fibro-endoscopic evaluation of swallowing

Alessia Zanon

alessiazanon@hotmail.it

1 Surgical Department, Otorhinolaryngology Unit, General Hospitals of Dolo and Mirano, Via Mariutto 76, 30035 Venice, Mirano, Italy

2 Neuroimaging Research Unit, Division of Neuroscience, IRCCS San Raffaele Scientific Institute, Milan, Italy

3 Vita-Salute San Raffaele University, Milan, Italy

4 Intensive Care Unit "U.O.C. Anestesia E Rianimazione, Department of Surgery, Padua University Hospital, Padua, Italy

5 Neurology Unit, Milan, Italy

6 Neurophysiology Unit, Milan, Italy

7 Neurorehabilitation Unit, IRCCS San Raffaele Scientific Institute, Milan, Italy
(FEES) on the day after, documenting poor control of the oral and oropharyngeal phases, laryngeal penetration, and inhalation by gravity (Penetration- Inhalation Scale, [PAS] 8) [11]. The patient immediately initiated dry swallow rehabilitation. Feeding was administered exclusively through a nasogastric tube (NGT) or intravenously (after the patient removed it, on day 26).

Bedside FEES was repeated after one month, but despite a substantial improvement of the oral and oropharyngeal phases, the patient still presented inhalation for solids and liquids-(PAS 8) (Fig. 1). The bronchoscope touch induced neither laryngeal sensitivity nor cough reflex, and the instrument could easily cross vocal folds. Absolute fasting was confirmed, and percutaneous endoscopic gastrectomy (PEG) was suggested.

The neurological examination did not reveal deficits in the cranial nerves, excepted for absent gag reflex. Brain MRI disclosed small non-specific periventricular white matter hyperintensities on T2-weighted sequences (Fig. 1). After gadolinium administration, neither lesions nor other brain structures showed contrast-enhancement.

In physiological conditions, swallowing results from sensorimotor coordination of more than thirty muscles and six cranial nerves [4].

After Acute Respiratory Syndrome Disease (ARDS), about $30 \%$ of intubated patients develop dysphagia with a consequent risk of aspiration pneumonia, delayed oral feeding, weight loss, and increased mortality [2, 6, 9].

In this patient, post-intubation dysphagia might be due to pharyngolaryngeal trauma, neuromuscular weakness, and altered sensitivity (neurosensory dysphagia) [6].

Pharyngolaryngeal trauma usually affects the oral and pharyngeal phases of swallowing and resolves within few days [6], possibly explaining the alterations of the first FEES. Conversely, neuromuscular weakness usually depends on muscle atrophy following prolonged intubation [10], which is not our case. 
MRI

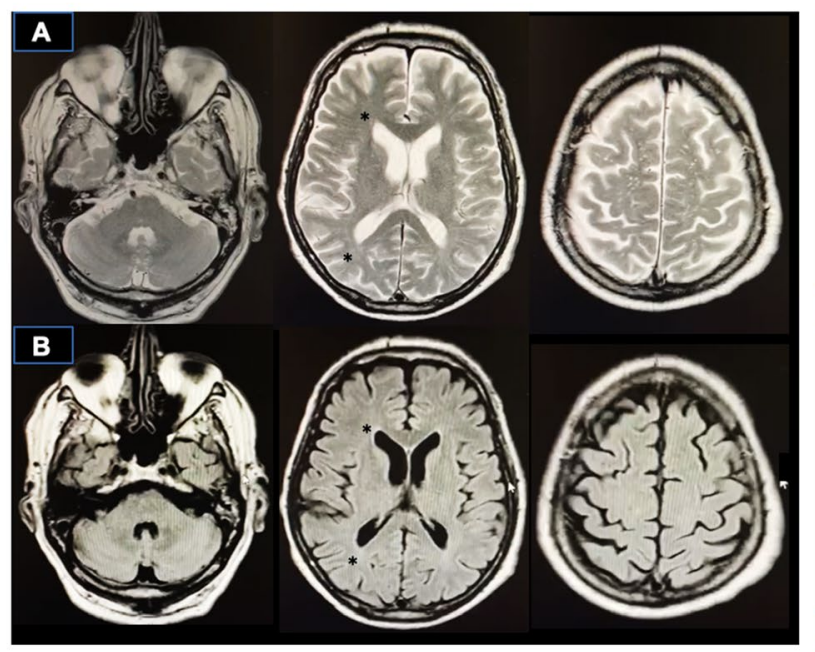

G
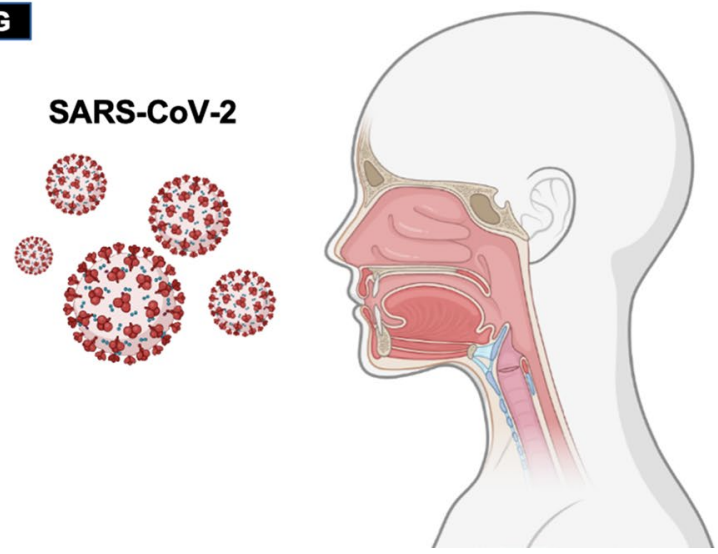

FEES
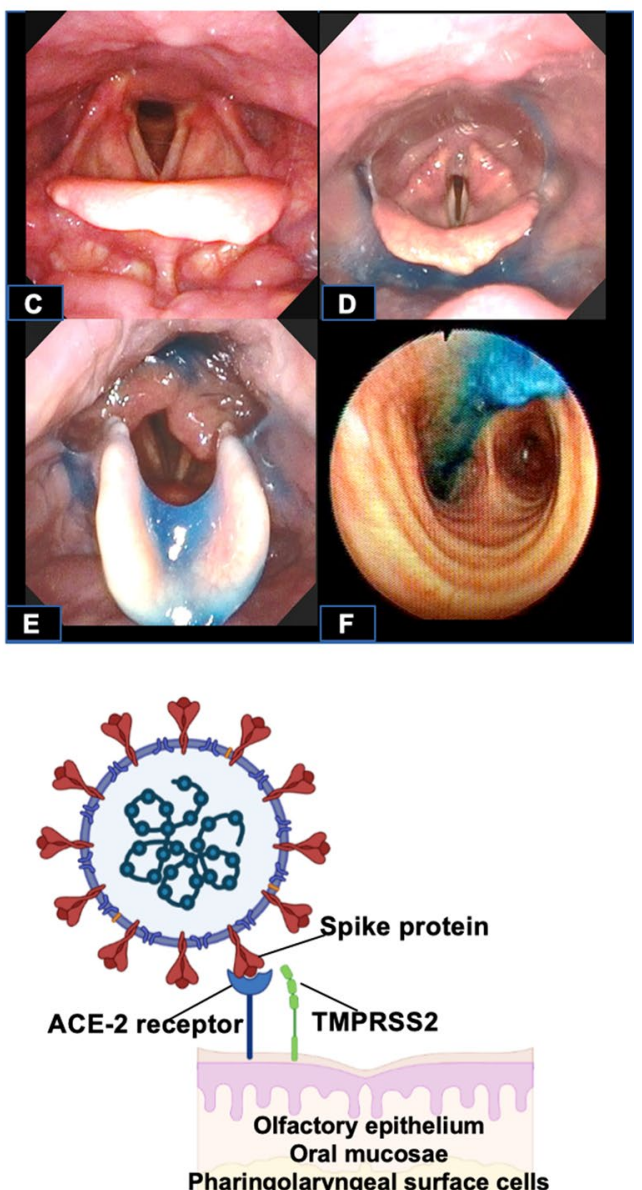

Fig. 1 FLAIR (a) and T2-weighted (b) brain images on MRI, showing mild non-specific periventricular hyperintensities (*). Images from the FEES, disclosing a normal anatomy before deglutition (c), bolus stasis in glosso-epiglottic valleculae and pyriform sinuses (d), initial penetration (e) and inhaled material reaching the trachea and right main stem bronchus (f). Panel $G$ represents the mechanism of infection, starting with the binding between the spike protein of SARS-CoV-2 and ACE-2 receptor and TMPRSS2, which

In line with our experience, neurosensory dysphagia manifests with aspiration consequent to impaired control of the bolus from the oral to the pharyngeal phase but resolves in one week [6].

Patients with Severe Acute Respiratory Syndrome Corona Virus 2 (SARS-CoV-2) infection can experience long-lasting neurological symptoms, including loss of smell (anosmia) and taste (ageusia) [8]. The olfactory epithelium and the oral mucosae express the Angiotensin-Converting Enzyme 2 (ACE-2) receptor and Transmembrane Protease Serine 2 (TMPRSS2) proteins, which are entry route for the virus [12]. Interestingly, both the pharynx and larynx surface cells express these proteins [12] (Fig. 1) and have a mutual are expressed by the olfactory epithelium, the oral mucosae and the pharingolaryngeal surface cells. Created with BioRender.com. MRI Magnetic Resonance Imaging; FLAIR Fluid Attenuated Inversion Recovery; FEES Fibro-Endoscopic Evaluation of Swallowing; NGT Naso Gastric Tube; SARS-CoV-2 Severe Acute Respiratory Syndrome Corona Virus 2; ACE-2 Angiotensin-Converting Enzyme 2; TMPRSS2 Transmembrane Protease Serine 2

sensory innervation through the superior laryngeal branch of the vagus nerve [1].

Against this background, the atypical duration of neurosensory dysphagia and the documentation of dysphagia cases during COVID-19 infection [5] might suggest a common pathogenic background of anosmia, ageusia, and neurosensory dysphagia.

Therefore, early evaluation of swallowing is mandatory in COVID-19 extubated patients to recognize possible neurological damage (and consequent slower recovery) [3].

When abnormal findings are present, bedside FEES could be the most appropriate second-level examination [5], even if at high-risk for generating SARS-CoV-2 aerosols [7]. 
In our opinion, the best timing for FEES could be 7-10 days after the extubation of COVID-19 patients. In this time window, most dysphagia causes resolve spontaneously (i.e., laryngeal paresis, pressure ulcers) [6], and the virus clearance might be complete.

If post-intubation dysphagia is confirmed, a NGT can be a useful measure, but it can delay swallowing rehabilitation in the presence of reduced sensitivity. In these patients, PEG positioning could be the best option. After discharge, serial FEES can detect deglutition improvements and lead to prompt PEG removal.

Funding The authors received no specific funding for this work.

Data availability Data are available on request from the authors.

Code availability Not applicable.

\section{Declarations}

Conflicts of interest The authors declare that they have no conflict of interest.

Ethical approval All procedures performed in this study were in accordance with the ethical standards of the institutional and/or national research committee and with the 1964 Helsinki Declaration and its later amendments or comparable ethical standards.

Informed consent The patient gave consent to participate in the study and to publish the data.

Consent to participate The patient gave consent to participate in the study.

Consent for publication The patient gave his informed consent to publish the data.

\section{References}

1. Bradley RM (2000) Sensory receptors of the larynx. Am J Med 108(Suppl 4a):47S-50S
2. Brodsky MB, Huang M, Shanholtz C, Mendez-Tellez PA, Palmer JB, Colantuoni E, Needham DM (2017) Recovery from dysphagia symptoms after oral endotracheal intubation in acute respiratory distress syndrome survivors. A 5-year longitudinal study. Ann Am ThoracSoc 14:376-383

3. Carda S, Invernizzi M, Bavikatte G, Bensmail D, Bianchi F, Deltombe T, Draulans N, Esquenazi A, Francisco GE, Gross R, Jacinto LJ, Moraleda Perez S, O'Dell MW, Reebye R, VerduzcoGutierrez M, Wissel J, Molteni F (2020) COVID-19 pandemic. What should physical and rehabilitation medicine specialists do? A clinician's perspective. Eur J PhysRehabil Med 56:515-524

4. Costa MB (2018) Neural control of swallowing. ArqGastroenterol 55:61-75

5. Dziewas R, Warnecke T, Zurcher P, Schefold JC (2020) Dysphagia in COVID-19 -multilevel damage to the swallowing network? Eur J Neurol 27:e46-e47

6. Frajkova Z, Tedla M, Tedlova E, Suchankova M, Geneid A (2020) Postintubation dysphagia during COVID-19 outbreak-contemporary review. Dysphagia 35:549-557

7. Kimura Y, Ueha R, Furukawa T, Oshima F, Fujitani J, Nakajima J, Kaneoka A, Aoyama H, Fujimoto Y, Umezaki T (2020) Society of swallowing and dysphagia of Japan: position statement on dysphagia management during the COVID-19 outbreak. Auris Nasus Larynx 47:715-726

8. Lechien JR, Chiesa-Estomba CM, De Siati DR, Horoi M, Le Bon SD, Rodriguez A, Dequanter D, Blecic S, El Afia F, Distinguin L, Chekkoury-Idrissi Y, Hans S, Delgado IL, Calvo-Henriquez C, Lavigne P, Falanga C, Barillari MR, Cammaroto G, Khalife M, Leich P, Souchay C, Rossi C, Journe F, Hsieh J, Edjlali M, Carlier R, Ris L, Lovato A, De Filippis C, Coppee F, Fakhry N, Ayad T, Saussez S (2020) Olfactory and gustatory dysfunctions as a clinical presentation of mild-to-moderate forms of the coronavirus disease (COVID-19): a multicenter European study. Eur Arch Otorhinolaryngol 277:2251-2261

9. Mohan R, Mohapatra B (2020) Shedding light on dysphagia associated with COVID-19: the what and why. OTO Open 4:34770

10. Rassameehiran S, Klomjit S, Mankongpaisarnrung C, Rakvit A (2015) Postextubation dysphagia. Proc (BaylUniv Med Cent) 28:18-20

11. Rosenbek JC, Robbins JA, Roecker EB, Coyle JL, Wood JL (1996) A penetration-aspiration scale. Dysphagia 11:93-98

12. Vergara J, Lirani-Silva C, Brodsky MB, Miles A, Clave P, Nascimento W, Mourao LF (2020) Potential influence of olfactory, gustatory, and pharyngolaryngeal sensory dysfunctions on swallowing physiology in COVID-19. Otolaryngol Head Neck Surg 3:194599820972680 